\title{
Non-culpable ignorance and HIV criminalisation
}

\author{
Jessica Flanigan
}

\begin{abstract}
Correspondence to Jessica Flanigan, Jepson School of Leadership Studies; Philosophy, Politics, Economics, and Law, Jepson Hall, University of Richmond, 28 Westhampton Way, Richmond, VA 23173, USA; flanigan@richmond.edu
\end{abstract}

Received 21 September 2012 Revised 2 June 2014 Accepted 18 August 2014 Published Online First 4 September 2014

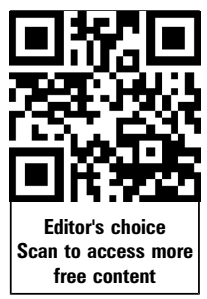

\section{SLinked}

- http://dx.doi.org/10.1136/ medethics-2012-100894 Ethics 2014;40:798-801.

\section{ABSTRACT}

In this essay, I argue that any legal framework that addresses sexual transmission of HIV should be sensitive to the way that culpability can be mitigated by moral and factual ignorance. Though it is wrong to transmit HIV, public officials should be wary of criminalising transmission because people with HIV may be excused if they suffer from blameless moral or factual ignorance. I begin with the widely shared premise that blameless ignorance about one's HIV status is an excuse for sexual transmission of infections. I then extend this premise to other kinds of non-moral ignorance about HIV. Next, I argue that blameless moral ignorance also excuses transmission of HIV. There is some evidence of significant blameless non-moral and moral ignorance about HIV transmission. In these cases, transmission is excused. In light of the presence of moral and non-moral ignorance about HIV, I conclude that public health officials should encourage moral deliberation about HIV transmission and also that criminal penalties for HIV transmission are unwarranted even in some cases of knowing or intentional transmission.

Any legal framework that addresses sexual transmission of HIV should be sensitive to the way that culpability can be mitigated by factual and moral ignorance. Though it is wrong to transmit HIV, public officials should be wary of enforcing criminal penalties because even people who knowingly or intentionally transmit HIV may be excused if they are blamelessly ignorant of relevant non-moral and moral considerations. I begin with the widely shared premise that blameless ignorance about one's HIV status is an excuse for sexual transmission of infections. I then extend this premise to other kinds of non-moral ignorance. Next, I argue that blameless moral ignorance also excuses transmission of HIV. There is some evidence to suggest that significant blameless non-moral and moral ignorance about HIV transmission persists today in some contexts. In these cases, transmission is excused.

The ethics and institutional implications of HIV transmission that results from moral ignorance have not been addressed in previous discussions of the topic. The presence of moral ignorance about HIV transmission calls for two policy proposals. First, public health campaigns should promote awareness of moral as well as non-moral facts about HIV transmission, or at least encourage more deliberation about the ethics of transmission. Second, even criminal penalties for knowing HIV transmission may be unjustified if the transmitter is blamelessly ignorant of the moral facts. In light of the presence of moral and non-moral ignorance about HIV, I conclude that law enforcement should risk failing to punish wrongful HIV transmitters rather than punishing those who are not culpable for transmission. This argument therefore lends further support to calls for an end to HIV criminalisation policies throughout the world, and at minimum justifies limited enforcement of those policies. ${ }^{1}$

\section{NON-CULPABLE IGNORANCE}

Ignorance lessens a person's culpability for an act, especially if she is not culpable for the ignorance from which she acts. For example, if I am not aware that you are allergic to peanuts and I make a cake that has peanut butter in it and serve it to you, I may be excused for making you sick because I was unaware of your allergy. In this case, I am not culpable for my ignorance so my harming you is excused, though I would have acted wrongly if I knew about your allergy. This principle can extend to HIV transmission when the transmitter is ignorant of relevant facts, such as her HIV status or the chance of transmission.

Non-moral ignorance is not always an excuse. If a physician does not know that a patient is allergic to penicillin, and is too lazy to ask her, he would be blameworthy for his factual ignorance and therefore blameworthy for injecting her with a drug that is harmful to her. When ignorance is wilful or stems from negligence, it does not count as an excuse. This is the intuition that leads us to blame people for their negligence when they 'should have known better' but not in cases when knowing the potential for harm is impossible. Attributions of blame for sexual transmission of infections reflect this principle. ${ }^{2}$ A man with human papillomavirus (HPV) cannot be tested for the infection, so he cannot be blamed if he unknowingly transmits HPV to his partner. Yet unknowing transmission is not always excused. For example, people with reason to believe they have HIV may be culpable for negligence and therefore blameworthy for transmission if they chose to remain wilfully ignorant. $^{2}$

It is difficult to discern when ignorance is blameworthy in cases of HIV transmission. Recently, $50 \%$ of Americans reported that they had never had an HIV test, with the majority claiming that they were not tested because they did not think they were at risk. ${ }^{3}$ Although HIV testing is becoming more accessible and widely used, especially with the introduction of over the counter tests, a persistent minority of high-risk populations continue to refrain from testing. ${ }^{4} 5$ Potentially, these statistics reflect some instances of wilful ignorance, but people may also refrain from testing for other reasons, such as the cost of testing or misguided beliefs about whether one is at risk. 
Even if a person knows his or her health status, knowing transmission may be excused on the basis of other kinds of blameless non-moral ignorance, such as ignorance about the probability of transmission. For example, in a recent poll, 21\% of Americans said they thought a person could get AIDS from sharing a drinking glass. ${ }^{3}$ On the other hand, a quick online search will reveal message boards that are filled with men who sincerely ask if it is possible to get HIV from vaginal sex with a woman.

Ignorance about these non-moral aspects of HIV transmission may be excused if accurate information is inaccessible. There is some evidence to suggest that accurate information about HIV is difficult to access. For example, 57\% of Americans said they were exposed to little or no information about HIV/AIDS in the USA in the past year and 59\% had never talked to a healthcare provider about HIV/AIDS. ${ }^{3}$ Even with public health education in schools, misconceptions and myths about HIV and other sexually transmitted infections abound among adolescent populations in America. ${ }^{6}$ Information about HIV may be uniquely inaccessible because of the stigma that surrounds the topic. In light of this lack of information, false beliefs may be more excusable than if information were readily available.

False beliefs about HIV transmission are especially excusable where there are deliberate misinformation campaigns. For example, some NGOs that promote public health in Africa have been accused of discouraging condom use by distributing false information that suggested that condoms actually caused HIV transmission. ${ }^{7}$ Or, a person's community may perpetuate misinformation even if active misinformation is not encouraged. One respondent in a recent study of Haitian Americans' perceptions of AIDS said that 'I believe that what God created can be cured... like the common cold it can be cured, the flu, it can be cured, if it's God that created it, it can be cured.... 8 This respondent clearly knew how AIDS was transmitted, but also held that the disease was attracted to African Americans and gay people. ${ }^{8}$ In other parts of the world, discussions of HIV are discouraged because the disease is stigmatised, and these attitudes are correlated with widespread ignorance of HIV. ${ }^{9}$

\section{NON-CULPABLE MORAL IGNORANCE}

Gideon Rosen ${ }^{10}$ argues that blameless moral ignorance can be an excuse in addition to blameless non-moral ignorance. His examples focus on cases where the moral consensus is false, so it is difficult for an ordinary reasoner to see that he acts wrongly. Rosen illustrates this point with the example of ancient slaveholders who knew all the relevant facts about slavery-that it involved owning a person and treating that person like property-but were not aware that slavery was morally wrong. Just as factual ignorance could excuse accidental peanut poisoning, moral ignorance excuses ancient slaveholders.

In some parts of the world, moral ignorance about HIV transmission is prevalent. Consider some clear cases. Three-quarters of Christian leaders in Nigeria believe that AIDS is a divine punishment. $^{7}$ In America, 21\% of respondents agreed with the statement 'AIDS is punishment for the decline in moral standards'. ${ }^{3}$ These false moral beliefs can be found in other countries too, and may lead to reckless sexual behaviour by people who think they are morally virtuous. These Beliefs also demonstrate the poverty of many people's ordinary moral reasoning about HIV. ${ }^{9}$

We can also imagine more subtle forms of moral ignorance. Consider a prostitute who believes that those soliciting her for unprotected sex consent to the risks of transmission. Maybe she says to herself, 'I consent to the risks of pregnancy when I consent to unprotected sex, so too do my clients consent to the risks of transmission.' Suppose she and her coworkers discussed this issue, and they unanimously concluded that none of them have an obligation to disclose their HIV status to clients, just as their clients do not disclose their own status or other facts like whether they are able to father children. Her argument is coherent and understandable, even though it reaches the wrong moral conclusion.

Moral ignorance about HIV may be relatively more common than other kinds of moral ignorance since there are genuine controversies surrounding the ethics of HIV transmission. Burris and Weait ${ }^{11}$ appeal to the aforementioned pregnancy analogy to argue that whether HIV transmission counts as a wrongful harm depends in part on whether the consequence is perceived as expected or unexpected, deserved or undeserved. They argue that the victims of HIV transmission often share in responsibility for transmission, especially if they did not take steps to minimise the risk of onward transmission. Others disagree, and hold that victims of transmission are not responsible for becoming infected and that people with HIV always have a moral duty to disclose. ${ }^{2}$ Still others point out that even if victims bear some responsibility to protect themselves, they nevertheless do not waive their rights against transmission when they fail to practice safe sex, just as a person does not waive her rights against robbery when she walks through a dangerous neighbourhood. ${ }^{12}$ I highlight these debates to illustrate that when even bioethicists cannot come to an agreement about the relationship between culpability and HIV transmission, public officials should be reluctant to blame and convict morally ignorant HIV transmitters.

On the other hand, moral ignorance does not give people carte blanche to act however they want. If a person's moral ignorance is wilful or the result of negligence then she may not be excused-even if she did act from genuine moral or nonmoral ignorance. In addition, Alex Guerrero ${ }^{13}$ has argued that morally ignorant people may also be blameworthy if they acknowledge their moral ignorance and then behave recklessly in light of it. Guerrero advances the principle 'Don't Know, Don't Kill,' which states that if someone knows that she does not know the relevant moral facts (e.g. the moral status of a pig), then she is morally blameworthy if she chooses the morally risky action (e.g. killing a pig) unless she thinks there is something of comparable moral significance that tells in favour of the risky action.

Nevertheless, in a case where transmission is the result of non-culpable moral ignorance and the transmitter is conscientious insofar as he knows that conscientiousness is warranted, moral ignorance may excuse him for wrongful HIV transmission. For example, a person who decides not to get tested for HIV may be excused for her moral failure if she had good reason to believe upon consideration that testing was not morally required. However, if she is uncertain about the ethics of transmission or about the morality of remaining ignorant about her HIV status, then she has a duty be conscientious and refrain from potential transmission. In this case, conscientiousness may also require getting tested despite her moral uncertainty, notifying her partners that she does not know her HIV status, or practicing safe sex or abstinence in order to avoid potentially transmitting HIV. Even for those who are morally uncertain, it is clear that these costs of conscientiousness are not more morally significant than the risks of transmission. 
In some cases, conscientiousness in the face of moral ignorance is impossible. Peer-effects significantly influence moral and non-moral beliefs about HIV and other sexually transmitted infections. ${ }^{14}$ Insofar as people reliably have false moral beliefs that are affirmed by their communities, they do not even entertain the possibility that they are wrong. Recall the prostitute who considered the ethics of her behaviour but reached the wrong conclusion. In these cases, Guerrero's call ${ }^{13}$ for caution will remain unheard not because of her uncertainty but because she is certain about the wrong answer.

\section{PROMOTING MORAL KNOWLEDGE}

So far, I have argued that blameless moral and non-moral ignorance can excuse wrongful transmission, and that there is some evidence to suggest that people with HIV might face significant epistemic challenges. If this is the case, then some people who transmit HIV, even those who knowingly transmit it, may not be blameworthy insofar as they were blamelessly ignorant about the relevant moral and non-moral facts. The possibility of blameless moral and non-moral ignorance indicates a need for public awareness campaigns. Such campaigns would reduce wrongful transmission and help conscientious but misguided people avoid harming others.

In the first instance, misinformation about HIV should be discouraged and people should have access to all the facts about HIV transmission and avoidance. In most countries, public health campaigns already advertise non-moral information about HIV, but there are cultural factors that discourage widespread education. For example, religious communities may be resistant to public advertisements touting the benefits of condoms or education about sexually transmitted infections in public schools. These cultural barriers pose a challenge to public health officials, and insofar as a community's resistance to education amounts to wilful ignorance, they are blameworthy for their ignorance and therefore transmission is not excused in these cases. Another way of promoting awareness of relevant non-moral facts is to encourage people to get tested for HIV, though mere encouragement is not sufficient. Affordable access to HIV testing is also necessary to promote knowledge of one's HIV status. For this reason, public health policymakers should also make tests and their results widely available (e.g. through affordable over the counter HIV tests).

There is some evidence to suggest that public health campaigns and accessible testing have been successful at identifying people with HIV and reducing transmission among high-risk populations. ${ }^{15}$ If so, it would seem that transmission is often the result of non-culpable ignorance about non-moral facts. Once people are able to access the relevant non-moral facts about HIV transmission, they refrain from risky behaviours that could lead to transmission.

I have also suggested that some people wrongfully transmit HIV because of moral ignorance. In communities where moral ignorance is widespread, some morally ignorant people are potentially blameless. In these cases, public health officials should also encourage moral deliberation about HIV transmission. One concern about this kind of a proposal is that liberal societies may object to public officials imposing a moral framework on citizens. Such a policy may be accused of perfectionism or religious intolerance, for example. There are two responses to this worry about public moral education. First, the law takes a stand about morality in clear cases all the time. The criminalisation of wrongful conduct, for example, requires that public officials make judgments about right and wrong. Insofar as there are clear cases of false moral beliefs, such as racist, sexist or homophobic beliefs, officials can use public speech to discourage racism, sexism and homophobia. Turning to HIV, when people say that AIDS is divine punishment, it is unproblematic for public officials to encourage people to abandon this view and adopt true beliefs about morality. Public health officials also already promote awareness of moral principles when they encourage people to get tested and use condoms for avoiding wrongful transmission. The recent 'Know Your Status' advertisements in the USA and 'Better2Know' advertisements in the UK may be interpreted as making this kind of moral argument.

Still, the public promotion of true moral beliefs is more controversial than the promotion of moral conduct, and in some cases it may be inadvisable for public health officials to advertise controversial moral principles, such as the obligation to use condoms. Even if it were impermissible to promote some controversial moral principles, public health officials should at least promote moral deliberation, caution and conscientiousness. One challenge in promoting awareness is that many people do not reflect on the ethics of potential transmission, or they do not question whether their confidence in their moral beliefs justifies exposing others to potential harm. This lack of reflection is heightened by the fact that discussions of HIV are rare in the public sphere, so there are few opportunities for collaborative moral deliberation. At minimum, public awareness campaigns should encourage moral discussions, deliberation and conscientiousness. Officials need not take a stand on any particular moral principle to promote moral deliberation.

\section{A PROBLEM FOR CRIMINAL CONVICTIONS}

An activity should only be criminally prohibited if it is wrong, and people with excuses for wrongdoing should not face criminal penalties. ${ }^{16}$ The criminal law recognises that ignorance often counts as an excuse. Imagine a person is accused of murdering someone with toxic tea. If she did not know that she was serving her victim a toxin, then she is less culpable of the act. If she could not have known that the tea was toxic, then she is not culpable for the act at all. If she was negligent or wilfully ignorant, then she is culpable for the act. If she only suspected that killing via toxic tea was wrong, she should have been more cautious. The criminal law makes room for non-moral ignorance, and so too should moral ignorance count as an excuse or a mitigating factor in assessing the appropriateness of criminal penalties. $^{10}$

Many developed countries with low HIV prevalence enforce criminal penalties for knowing or intentional HIV transmission. ${ }^{17}$ For example, in Sweden, for every 1000 people living with HIV, six are convicted of HIV-specific offences. ${ }^{17} \mathrm{HIV}$ criminalisation is less prevalent in countries with higher rates of HIV prevalence, though recent legislation in Africa does enable greater criminalisation of transmission and exposure. ${ }^{17}$ If knowingly transmitting an infection is often wrong, then it may seem at first glance that these laws are justified. Sexually active people have special duties to avoid knowing transmission and investigate their health status, so even unknowing transmission of HIV can be morally wrong if the ignorance is a result of recklessness, or worse, wilful ignorance. These considerations might even suggest that the current standards of knowing or intentional criminalisation are too narrow, since unknowing transmitters can act wrongly too.

Yet, if I am right that many people are excusably ignorant of the moral and non-moral aspects of sexual transmission of infections, then the current standard of criminalisation is also potentially too broad. Plausibly, even some people who know they have HIV are excusably unaware of the relevant health facts and 
are also unaware of the relevant moral facts. Recall the previous example of the conscientious prostitute. She may acknowledge that it would be wrong for partners who are in a loving relationship to sexually transmit diseases but reasonably think that she has fewer obligations to her sexual partners than a girlfriend would. The possibility of blameless moral ignorance suggests that criminal convictions for transmission can be unjustified even in cases of knowing or intentional transmission.

This is not to say that criminalisation is intrinsically unjustified, but until a society achieves widespread moral and nonmoral awareness about HIV, law enforcement should be wary of enforcing criminal penalties. One may counter that criminal penalties can play the same epistemic role that I am proposing for public health officials. Perhaps convicting people for HIV transmission would effectively make people aware that knowing transmission is wrong. Yet, as O'Leary and Wolitski ${ }^{18}$ point out, people are often unaware of the laws that apply to HIV transmission, and having HIV-specific laws may also encourage people without HIV to develop a false sense of security, thereby compounding the public's unawareness of facts surrounding transmission. Moreover, surveys suggest that HIV-specific laws do not deter risky sexual behaviour. ${ }^{19}$ Just as potential transmitters should be cautious when they are uncertain about the moral facts, so too should public officials be cautious in enforcing criminal penalties when they are not sure about a person's level of knowledge or certainty about the moral facts.

These arguments against convicting people who knowingly or intentionally transmit HIV also justify reluctance to enforce criminal penalties in other cases of blameless moral ignorance, such as the toxic tea case above. On the other hand, if efforts to educate people about HIV transmission are successful then enforcement could be warranted in principle, as it is in other contexts where authoritative moral and non-moral public health information is accessible and ignorance is more likely blameworthy and wilful (e.g. ignorance about vaccines in some communities). Even in cases of blameworthy knowing and intentional transmission, there may be other reasons to resist criminal enforcement, such as concerns about stigmatisation, public health promotion or unfair penalties. ${ }^{20}$ The foregoing arguments about prevalent non-moral and moral ignorance also lend further support to more general resistance to criminalisation of HIV transmission insofar as criminal penalties could mistakenly convict transmitters who are blamelessly ignorant.

\section{CONCLUSIONS}

Moral and non-moral ignorance can sometimes excuse wrongdoing. In the case of HIV exposure, even knowing transmission may be excused if people suffer from moral or non-moral ignorance. I have suggested that blameless ignorance about various features of HIV transmission persists today in some contexts, and in these cases even knowing HIV transmission may be excused. These insights about the ethics of HIV transmission can also inform our understanding of when sexual transmission of other infections is excused, insofar as people are also ignorant about those diseases.
Two policy conclusions follow from this analysis. First, public health officials ought to promote knowledge of non-moral and moral facts about HIV transmission. Not only is it important to educate people about their HIV status and the importance of safe sex, it is also important to inform people that wilful ignorance and transmission is often wrong. Second, until the public's understanding of HIV improves, criminal law should not punish knowing or intentional HIV transmission when transmission is plausibly the result of blameless non-moral or moral ignorance.

\section{Competing interests None.}

Patient consent Obtained.

Provenance and peer review Not commissioned; externally peer reviewed.

\section{REFERENCES}

1 Burris $S$, Cameron $E$. The case against criminalization of HIV transmission. JAMA 2008;300(5):578-81.

2 Bennett R, Draper H, Frith L. Ignorance is bliss? HIV and moral duties and legal duties to forewarn. J Med Ethics 2000;26(1):9-15.

32012 HIVIAIDS poll-Washington Post-Kaiser Family Foundation. The Washington Post, 24 Jul 2012. http://www.washingtonpost.com/politics/polling/ 2012-hivaids-poll-washington-postkaiser-family/2012/07/24/gJQA3TGt0W_page. html

4 Grulich AE, Kaldor JM. Trends in HIV incidence in homosexual men in developed countries. Sex Health 2008;5(2):113-18.

5 Mounier-Jack S, Nielsen S, Coker R. HIV testing strategies across European countries. HIV Med 2008;9:13-19.

6 Cohall A, Kassotis J, Parks R, et al. Adolescents in the age of AIDS: myths, misconceptions, and misunderstandings regarding sexually transmitted diseases. J Natl Med Assoc 2001;93(2):64-9.

7 Caldwell JC. Rethinking the African AIDS epidemic. Popul Dev Rev 2000;26 (1):117-35

8 Marcelin LH, McCoy HV, DiClemente RJ. HIVIAIDS Knowledge and Beliefs Among Haitian Adolescents in Miami-Dade County, Florida. J HIV AIDS Prev Child Youth 2006:7(1):121-38.

9 Gaash B, Ahmad M, Kasur R, et al. Knowledge, attitude and belief on HIVIAIDS among the female senior secondary students in Srinagar district of Kashmir. Health Pop Perspect Issues 2003;26(3):101-9.

10 Rosen G. Skepticism about moral responsibility. Philos Perspect 2004;18 (1):295-313.

11 Burris S, Weait M. Criminalisation and Moral Responsibility for the Sexual Transmission of HIV. SSRN eLibrary, 2012. http://papers.ssrn.com/sol3/papers.cfm? abstract_id=2126714 (cited 19 Sep 2012).

12 Chalmers J. The criminalisation of HIV transmission. J Med Ethics 2002;28 (3):160-3.

13 Guerrero A. Don't know, don't kill: moral ignorance, culpability, and caution. Philos Stud 2007;136(1):59-97.

14 Shafer MA, Boyer CB. Psychosocial and behavioral factors associated with risk of sexually transmitted diseases, including human immunodeficiency virus infection, among urban high school students. J Pediatr 1991;119(5):826-33.

15 Kirby DB, Laris BA, Rolleri LA. Sex and HIV education programs: their impact on sexual behaviors of young people throughout the world. J Adolesc Health 2007;40 (3):206-17.

16 Husak D. Overcriminalization: the limits of the criminal law. 1st edn. USA: Oxford University Press, 2008:248.

17 Cameron S, Reynolds L. Global Criminalisation Scan Report. Amsterdam: Global Network of People Living with HIV, 2010.

18 O'Leary A, Wolitski RJ. Moral agency and the sexual transmission of HIV. Psychol Bull 2009;135(3):478.

19 Horvath KJ, Weinmeyer R, Rosser S. Should it be illegal for HIV-positive persons to have unprotected sex without disclosure? An examination of attitudes among US men who have sex with men and the impact of state law. AIDS Care 2010;22 (10):1221-8

20 Cameron E. Criminalization of HIV transmission: poor public health policy. HIV AIDS Policy Law Rev 2009;14(2):1, 63-75. 